\title{
STRATEGIES TO RESPOND TO CHANGE: AN EXPLORATORY STUDY
}

\author{
Bella BUTLER \\ Carolyn DICKIE \\ Marita NAUDÉ
}

\author{
Curtin University of Technology, Australia
}

\begin{abstract}
In this paper, focused on Western Australian organizations affected by the global financial crisis and their responses to the changing environment, there are significant practical and theoretical outcomes from an exploratory study. Theoretically, it has identified a deeper understanding of how organizations respond to, and manage, change in times of uncertainty; it complements existing literature by extending discussions about decision-making, re-allocation of resources, communication strategies and management of concerns and attitudes of employees within specific workplace contexts. Similarly, it contributes to extant literature on the change process and, potentially, assists in the development of a framework to inform the completion of successful change events. Practically, it is significant that participating organizations receive aggregated data that help identify elements of successful change practices that can be implemented to assist managers. The paper comprises two parts; the first highlights relevant literature which provides the context for subsequent discussion and in the second part the research methodology, findings and overall conclusions are discussed.
\end{abstract}

Key words: strategies, change, crisis, uncertainty, Western Australia.

\section{INTRODUCTION}

The purpose in this paper is to explore the role of strategies of firms in their ability to respond to environmental turbulence so as to sustain a competitive advantage. The study began with investigation of the role of dynamic capabilities in assisting firms to operate in the dynamic environment and deal with external complexity and uncertainty. It was continued by exploring the role of learning approaches and, in particular, the ability of firms to develop new capabilities and acquire resources in making effective responses to environmental pressures for change. Consequently, in the paper the approach to organisational learning used by a variety of Western Australian organisations was examined. Finally, conclusions were suggested as a result of evidence from the selected case study on how environmental responsiveness of firms can be achieved by ongoing learning and training, consultancy and collaboration with key stakeholders, thereby co-creating services for major customers, promoting customers' involvement and fostering knowledge exchange.

\section{SEARCHING FOR STRATEGIES TO RESPOND TO CHANGE}

Nowadays corporations are challenged by dynamic environments with a rapid speed of changes, burgeoning complexity and increased uncertainty. Firms must be able to cope with unplanned situations which cannot be predicted in advance. As Tsoukas (1996, p.22) describes it, "firms are faced with radical uncertainty: they do not know, they cannot know, what they need to know". Hence, organizations are engaged in discovering the unknowable and their strategy has to assist them in this process in order to enable their firms to manage crises.

Management scholars are trying to understand how companies cope with environmental changes, what do firms learn from the changing environment and how the environment affects the firms' learning processes (Hitt et al., 1998; Hong, Kianto \& Kyläheiko, 2008; Minzberg, 1994; Powel, 1990; Stacy, 1991). Extant studies have shown that turbulent environments do not remain in the same state long enough for an organization to be able to find a favourable competitive position and exploit it (Eisenhardt \& Brown, 1998; Fines, 1998). The limited timeframe challenges firms to respond quickly and with resilience to external changes. As Hamel and Valikangas (2003, p.53) assert, "in a turbulent 
age, the only dependable advantage is a superior capacity for reinventing your business model before circumstances force you to. Achieving resilience is not easy". This view is supported by Eisenhardt (1998) who believes that to survive in such a fast-paced environment, firms must embed flexibility into their strategic actions. Undoubtedly, flexibility in resource deployment may explain why some firms move into new niches (Eisenhardt \& Martin, 2000). In addition, flexibility in response actions enables firms to develop and sustain their own competitive advantage, as well as erode the advantages of competitors (Eisenhardt, 1998; Young et al., 1996). Strategic flexibility also refers to the ability of organisations "to jump from one opportunity to the next, going with the flow of the market" (Cunha 2004, p.275). Consequently, "turbulent environments call for organisations to be able to detect and create new opportunities and then select those that are worthy of actual resource allocation in order to be exploited for the firm's benefit" (Cunha 2004, p.278) and the ability of firms to benefit from new opportunities requires them to develop new resources and dynamic capabilities over time rather than protect their unique resources.

\section{The dynamic resource-based view of the firm and dynamic capabilities}

The resource-based view (RBV) of the firm emphasises that the competitive advantage of firms is based on their ability to possess valuable, rare, costly-to-imitate and non-substitutable resources and capabilities (Barney, 1986; Penrose, 1959; Rumelt, 1984; Wernerfelt, 1984). Understanding this version of 'competitive advantage' promotes the deployment and protection of unique resources rather than the need for resources and competencies to progress over time (McEvily, Eisenhardt \& Prescott 2004; Døving \& Gooderham 2008). Rapid, unpredictable environmental changes and market complexities require firms to accumulate competitive advantage through a knowledge learning process able to respond rapidly to such dynamics. Therefore, the need to respond to the transforming environment is related to the view of strategic ambidexterity (Dos 2007; Judge \& Blocker 2008).

There is an extensive body of literature on the implications of dynamic capabilities and accumulation processes (Bierly \& Chakrabarti 1996; Eisenhardt \& Martin 2000; Luo 2000; Savory 2006; Teece, Pisano \& Shuen, 1997; Tripsas 1997). Dynamic capabilities of firms are related to process, position and path (Liu, 2005). Teece, Pisano and Shuen (1997) stress that firms need to pay closer attention to the paths of behaviours and activities, and depend on paths of influence as possible future orientations. Boisot (2007) continues by pointing at future orientations of a capability as "a strategic skill in the application and integration of competences". This view is supported by Savory (2006, p.1055) who stressed that "competences are potential components of higher level capability" and capabilities are built around groups of competences.

Savory (2006) distinguished among the terms resource, competence and capability. He defined resources as factors that are owned and controlled by the organisation or available through alliances and other external relationships, whereas competence is "the ability to use the resources to an acceptable level of performance towards a desirable purpose" (Savory 2006, p.1055). Further, he defined capabilities as "the ability to operate a specific configuration of an organisation's set of resources" (ibid.) and dynamic capabilities as "the ability to reconfigure both the use and coordination of a specific configuration and the development of new configurations of resources, according to changes in the organisation's environment and strategic direction" (ibid.).

Previously, Teece, Pisano and Shuen (1997, p.516) defined dynamic capabilities as "the firm's ability to integrate, build, and reconfigure internal and external competencies to address rapidly changing environment". This argument was developed further by Eisenhardt and Martin (2000, p.1106) who stressed that the "value [of dynamic capabilities] for competitive advantage lies in the resource configuration, not in the capabilities themselves." Lansiti and Clark (1994) added to the early understanding of dynamic capability by referring to it as the firms' ability to regenerate its knowledge base (cited in Døving \& Gooderham 2008). Eisenhardt and Martin (2000) emphasised that dynamic capabilities consist of specific strategic and organisational processes that transfer resources into new competencies and that renew old ones; furthermore, they stress the role of dynamic capabilities as "the organisational and strategic routines by which firms achieve new resource configuration as markets emerge, collude, split, evolve and die" (Eisenhardt \& Martin 2000, p.1107). 
Winter (2000) notes alternative differences between dynamic capabilities; e.g., those indicated by routines sometimes can be invisible and unknown to the management, whereas control levers and deliberate outcomes of other dynamic capabilities are well-known. Døving and Gooderham (2008, p.845) refer to dynamic capabilities "as enduring routines, systems, and processes that are visible, known, and managerially intended as a means to achieving new resource configuration".

Jansson (2007) argues that the turning of organisational routines into organisational capabilities means that there is an expectation for organizations, managers and employees to act, make decisions and respond to the environment in a regular fashion. The word 'routine' is an expression of repeated behaviour; it means certain behaviour has been established, and the probability is high that it will be repeated in future. The reason for this is that routines contain codes for replicated behaviour, so that a routine through its code expresses an ability to behave in a certain way. An example of such a code is a thought style in the form of shared perceptions of daily practices. Thus, an organisational routine is either a capability to act repeatedly in a certain way, or a capacity to make certain decisions repeatedly based on specific knowledge (know-how) and in accordance with a certain style thereby confirming the basic code behind the behaviour. It is argued, therefore, that organisational routines that lead to competitive advantages in markets by creating customer value can be defined as a social organisational capability.

\section{Dynamic capabilities and organisational learning}

According to Leonard (1995), technological competences and capabilities of an organization are related to dynamic capabilities and consist of four interrelated 'key innovation activities': viz., problem solving, implementing and integrating, experimenting, and importing knowledge from outside the organisation. Savory (2006, p.1058-9) argues that "for many innovations the key process is not discovery of new knowledge but the use and modification of existing knowledge." Thus, knowledge may exist within the organization or may be acquired from the outside of it. Further, Savory (2006, p.1059) emphasizes the role of social dimensions of dynamic capabilities, whereby the "social dimension means that learning is a more complex process than individual learning ... which can be a social activity, particularly with respect to tacit knowledge". In the current study, it is argued that the learning of new knowledge and rediscovery of existing knowledge is happening in social networks.

From an industrial network perspective, interacting with others is the most fundamental activity of a company. Interaction among firms creates awareness of the rules, routines and procedures that actors should follow in order to learn from each other and the market (Dyer \& Wujin 2000; Gulati et al. 2000; Huemer 2004). The key research on the ability of firms to integrate in strategic business nets - Managing Strategic Nets: A Capability Perspective - was published by Möller and Svahn (2003), who identified the characteristics of the task organisations try to achieve through forming a specific strategic net; they defined strategic nets as "intentional structures that firms try to design deliberately for specific purposes" (Möller \& Svahn 2003, p.213). They continued by stating that "many strategic nets may also involve, at least temporarily, governmental organisations and university based research institutes" [and that the term 'net' is used to an intentional] "restricted group of actors" (Möller \& Svahn 2003, p.213).

Following the brief discussion of previous literature and for the purpose of this paper, the authors have accepted the following assumptions:

Under uncertainty organizations reconsider their traditional way of doing business and challenge their business model.

Uncertainty of the economic environment fosters organizational learning and creates favourable conditions for developing new capabilities by organisations.

Under uncertainty, organisations re-create their knowledge base and develop new capabilities by collaborating intentionally created "safety nets" - strategic nets.

From the assumptions, it was evident that organizations need to implement specific strategies to overcome and/or at least manage the impact and effects of changes in the business environment. Indeed, global financial crisis and economic uncertainty which followed after the crisis placed many organisa- 
tions in the situation of re-assessment of their strategies and business models. Some business partners and actors of business nets were affected more than the others and were unable to survive. As opposite, those who survived managed to identify new opportunities in a new -after the crisis- business environment, for example, an increased demand on higher quality products and decreased demand on a wider range of products; preparedness of contractors to negotiate decreased profit margin in order to maintain their customer base; higher involvement of customers in making specific requirements with regards to the ordered products etc.

On the basis of this logic, a set of research questions arose for the authors; these included:

How has the global financial crisis affected participating organizations?

What changes have organizations made in response to the global financial crisis?

How do participating organizations deal with employee emotions during times of uncertainty and change?

Consequently, in order to gain insight into the research questions, the main overall aim in this exploratory study was to develop a greater understanding of the dynamic capabilities of organizations; capabilities which firms develop in response to the external environment and, generally, lead to a smoother reconfiguration of an organization's structure and resources (including human resources).

\section{METHODOLOGY}

A case study design was selected for the study because the researchers aimed to gain an in-depth insight and understanding of the way that the changing environment affected organizations and their response to these changes within the context of a once-only case within a particular context and time as a starting point. The case study method had the value of enabling the authors to explore the content under study and, as argued by Yin (1984), retain the holistic characteristics of real-life events in fields such as organizational and managerial processes. He notes that while the results are not generalizable to populations, the case study compares to an experiment, where what is generalizable are the theoretical propositions.

Purposeful sampling (Creswell 2003, p.27; Creswell 1998, p.49) was used to select participants able to understand the overall aim of the study, its research questions and have experience of the research topic. Participants were invited through their association with the Change Management Institute in Western Australia, with various business managers and directors of organizations acting as contact persons. Participants were employees involved in, or impacted by, the strategic or implementation phases of the change process within their organization. A group of ten professionals formed the participants of the case study.

The current study, implemented within a context of discovery to gain evidence, used a phenomenological approach similar to that of Giorgi and Giorgi (2003); a method that has used an average sample size of 8.3 cases across seventy-six published studies (Russell 2006). Therefore, the use of ten purposefully selected cases was considered appropriate.

Within the case study research framework, a survey containing different sections was used as a collection tool. In Section A, biographical data such as gender, age and experience was collected through a range of closed questions to provide a context for the analysis and discussion of the findings. A combination of closed and open-ended questions was used in Section B; open-ended questions resembled a written narrative in asking participants to provide in their own words their personal perceptions, thoughts, ideas and approaches to provide richer data for analysis. According to Jabri (2006, p.364) understanding the culture of an organization is dependent largely on understanding the narratives from the employees on how they experience their workplace. Narratives provide knowledge on the environment within the context of the organization and are essential knowledge needed to understand policies and practices responsive to the needs of employees.

Section A was analysed through the SPSS quantitative data analysis package and reflected in tables and figures (basic quantitative, descriptive data). For the analysis of Section B, the researchers read through all the narratives and used 'thematic analysis' (Aronson 1994) to identify relevant tags (key 
words), links (codes) and categories (main themes). A most significant ethical issue in the study was the need to ensure participant anonymity and confidentiality as some data might contain sensitive or strategic information. Therefore, no identifying information appeared on or was requested in the survey and participation was voluntary. Consent to participate was assumed when an employee returned the survey and all hard-copy or e-mailed surveys were returned directly to the researchers. The Curtin University Human Research Ethics Committee had approved the study as being managed according to its guidelines.

\section{RESEARCH FINDINGS}

As shown in Exhibit 1, the research participants comprised both females and males with more males as expected in senior positions in organisations. The ages of participants was spread from the twenties to over fifty years of age with the largest group being in the 40-49 years range.

\begin{tabular}{|c|c|c|}
\hline \multicolumn{2}{|c|}{ Exihibit 1. Participant' Gender and Age. } \\
\hline Characteristic & Variable & Number \\
\hline Gender & Female & 3 \\
& Male & 7 \\
Age & $20-29$ & 1 \\
& $30-39$ & 3 \\
& $40-49$ & 4 \\
& $50+$ & 2 \\
\hline
\end{tabular}

Similarly, there was a range of industries represented in the survey, as shown in Exhibit 2, the advantage being that, in an exploratory study there was the potential for a variety of relevant responses. Exhibit 3 was used to present specific information regarding the participants' position and time employed in their organisation. A strong majority of participants held upper management positions and had been in their current job for less than three years, even though they had spent from less than three to more than 10 years in the organisation.

When asked about the effects of the global financial crisis on their organisation, all respondents reported a degree of 'downturn'. However, they reported that the 'downturn' varied; e.g., it was Slight (3), Moderate (4) or Significant (3). As shown in Exhibit 4, the economic downturn factors tended to be evenly divided between the categories of finance and work performance, although $20 \%$ of the participants' responses related to effects related to 'customers'.

\begin{tabular}{|c|c|c|}
\hline \multicolumn{3}{|c|}{ Exihibit 2. Participant' Industry } \\
\hline Industry & Focus & Number \\
\hline Mining & Iron Ore & 1 \\
\hline Electricity, Gas, Water \& Waste Services & $\begin{array}{l}\text { Water \& Waste } \\
\text { Water, Waste \& Drainage } \\
\text { Energy Logistics }\end{array}$ & $\begin{array}{l}1 \\
1 \\
1\end{array}$ \\
\hline Construction & Concrete Manufacture & 1 \\
\hline Retail Trade & Hardware & 1 \\
\hline Transport, Postal \& Warehousing & Rail Engineer & 1 \\
\hline Financial and Insurance Services & $\begin{array}{l}\text { Banking } \\
\text { Retail Banking }\end{array}$ & $\begin{array}{l}1 \\
1\end{array}$ \\
\hline Health Care \& Social Assistance & Aged, Disabled, Ill \& Infirm Care & 1 \\
\hline
\end{tabular}




\begin{tabular}{|l|l|c|}
\hline \multicolumn{2}{|c|}{ Exihibit 3. Participant' Position in Organisation } \\
\hline \multicolumn{1}{|c|}{ Characteristic } & \multicolumn{1}{|c|}{ Variable } & Number \\
\hline Organisational Level & Supervisory & 1 \\
& Middle management & 7 \\
& Upper management & 0 \\
\hline Time in Organisation & Executive & 1 \\
& Less than 3 years & 4 \\
& 3-5 Years & 2 \\
\hline Time in Current Job & 6-10 Years & 3 \\
& 10+ Years & 6 \\
& Less than 3 years & 2 \\
& 3-5 Years & 1 \\
\hline
\end{tabular}

The types of decisions used by the organisation in responding to the economic downturn were posited as being strategic (long-term), improvisation (short-term) or a combination of both. The initial response by participants indicated that no organisation used strategic or improvised decisions alone; i.e., all ten organisations used a combination of decision types to maximise their outcomes. Moreover, the respondents' answers indicated an equal number of specific decisions in the 'strategic' (6) and 'improvisation' (6) categories. In addition, there were 9 action decisions nominated regarding a 'staff' category (Exhibit 5). The suggestion is that staffing was a central area of operational change in the organisation's response to the economic strictures.

Exhibit 6 presents specific actions that were effected by organisations in responding to the financial crisis; some organisations used more than one response, so the total number of responses does not add to ten. 'Downsizing' was the most common response by organisations, though the 'Form alliances' and 'Restructure'

actions were used by more than one organisation; the use of a 'Merger' involved only one organisation. However, in addition to the four categories suggested, participants listed six 'Other' responses, as shown in Exhibit 6.

\begin{tabular}{|l|l|}
\hline \multicolumn{2}{|c|}{ Exihibit 4. Economic Downturn Factors } \\
\hline \multicolumn{1}{|c|}{ Links } & \multicolumn{1}{|c|}{ Categories } \\
\hline Revenue inflow & \\
Cost of money & \\
Loan defaults & Finance \\
Reduction in opportunities & \\
Cash-based deposits & \\
Funding opportunities & \\
Sales & \\
Government funding & \\
External funding & \\
\hline Vigilance & \\
Efficiencies & \\
Urgency & Work Performance \\
Slowdown & \\
Nowhere near peak & \\
Trouble with suppliers & \\
Necessary maintenance & \\
Building downturn & \\
Contracts & \\
\hline Customer impact & \\
Demand for care services & Customers \\
Consumer confidence & \\
Use of company facilities & \\
\hline
\end{tabular}




\section{Exihibit 5. Categories of Decisions}

\begin{tabular}{|l|l|}
\hline \multicolumn{1}{|c|}{ Links } & Categories \\
\hline Borrowing of funds & Strategic \\
Credit/lending policies & \\
Longer-term impacts & \\
Quality human resources & \\
Rethinking core business & \\
Divisions joined together & \\
\hline Moratorium on new equipment & \\
Moratorium on investments & Improvisation \\
Reduced duplication of services & \\
Budget cuts & \\
Retail prices reduced & \\
New equipment orders on hold & \\
\hline Reduce staff numbers & \\
Staff reduction & \\
More accountability & Staff \\
Retrenched staff & \\
No replacement of staff & \\
No overtime & \\
Staff forced to take leave & \\
Conditions of employees reduced & \\
\hline
\end{tabular}

\begin{tabular}{|c|c|c|c|}
\hline \multicolumn{4}{|c|}{ Exihibit 6. Organisational Responses to Downturn } \\
\hline & Action & Number & Details \\
\hline $\begin{array}{l}\text { Downsize } \\
\text { Restructure } \\
\text { Merge } \\
\text { Form alliances } \\
\text { Other }\end{array}$ & $\begin{array}{l}4 \\
2 \\
1 \\
3 \\
4\end{array}$ & & $\begin{array}{l}\text { 'Other' responses included: } \\
\text { * Business improvement } \\
\text { * Use of suppliers } \\
\text { * Replacement of staff by natural attrition } \\
\text { * Rethink core business } \\
\text { * Reduce duplication of Services } \\
\text { * Conservative expansion to take advantage of } \\
\text { lower costs }\end{array}$ \\
\hline
\end{tabular}

When asked about what had triggered the organisation to make decisions for change, fourteen different items were linked from the key words provided by participants (Exhibit 7). The links were placed into one of the three categories of internal or external pressures or standard organisational practices.

\begin{tabular}{|l|c|}
\hline \multicolumn{1}{|c|}{ Exihibit 7. Reasons for Organisational Decisions } \\
\hline \multicolumn{1}{|c|}{ Links } & \multicolumn{1}{|c|}{ Categories } \\
\hline $\begin{array}{l}\text { Need to stay in business - no other way } \\
\text { Self-protection \& survival } \\
\text { State government decision }\end{array}$ & External pressures \\
\hline $\begin{array}{l}\text { Financial sustainability } \\
\text { Desire to maintain service levels } \\
\text { Monthly profit figures } \\
\text { Efficiency measuring } \\
\text { Amount of work in progress }\end{array}$ & \\
\hline $\begin{array}{l}\text { Constant review } \\
\text { Constant monitoring } \\
\text { Shareholder input } \\
\text { Management review } \\
\text { Review of needs of workers } \\
\text { Focus on business opportunities }\end{array}$ & \\
\hline
\end{tabular}


When asked if there was a generally accepted procedure to deal with chosen strategies in their organisation, only eight of the ten replied in the affirmative. Nevertheless, twelve different links were identified from the participants' responses (Exhibit 8). The three categories of organisational procedures were identified as arising from management processes, factors related to decision-makers and a number of non-formal procedures. Participants reported five information sources that were used by the organisation in order to investigate the need for changes to strategy (Exhibit 9). Most organisations used more than one source, which accounts for the tally of sources exceeding ten. In addition, the 'other' category had two items, each of which was nominated by only one person. The responses indicate that external market analysis and the driving vision of top management are the two major information sources for prosecuting change.

Another aspect of effecting change in an organisation relates to the need for effective communication of the change decision and operational imperatives (Results are reported in exhibit 10). In the current study, 9 out of 10 participants reported that use of 'meetings' was essential. At the next level, each nominated on seven occasions were use of 'email', 'intranet' and 'employee training sessions'. In retrospect, the item 'employee training sessions' may have been better listed as 'employee information

\begin{tabular}{|l|l|}
\hline \multicolumn{2}{|c|}{ Exihibit 8. Procedures to Implement with Strategies } \\
\hline \multicolumn{1}{|c|}{ Links } & \multicolumn{1}{|c|}{ Categories } \\
\hline $\begin{array}{l}\text { Standard management processes } \\
\text { Strategic planning processes } \\
\text { Industry codes and explanations } \\
\text { Clear strategic plan } \\
\text { Always reviewed and followed }\end{array}$ & Management processes \\
\hline $\begin{array}{l}\text { Enhanced to take account of factors specific to alliance partners } \\
\text { Decisions made by the Board } \\
\text { Decisions by senior staff }\end{array}$ & Decision-maker factors \\
\hline $\begin{array}{l}\text { Very quick decisions } \\
\text { Knee jerk reactions } \\
\text { Not much planning }\end{array}$ & Non-formal \\
\hline
\end{tabular}

\begin{tabular}{|l|c|}
\hline \multicolumn{2}{|c|}{ Exihibit 9. Information Sources for Strategy Change } \\
\hline \multicolumn{1}{|c|}{ Information Sources } & No. x/10 \\
\hline Executive network contacts & 3 \\
Driving vision of top management & 5 \\
Analysis by organisation's marketing department & 4 \\
External market analysis & 6 \\
Low level (bottom up) & 5 \\
Other- & 2 \\
$\quad$ mining slowed & \\
government policy & \\
\hline
\end{tabular}

\begin{tabular}{|l|c|}
\hline \multicolumn{2}{|c|}{ Exihibit 10. Organisational Change Communication } \\
\hline \multicolumn{1}{|c|}{ Type of Communication } & No. x/10 \\
\hline Meetings & 9 \\
Email & 7 \\
Intranet & 7 \\
Internal newsletter & 3 \\
Internal memorandum & 4 \\
Employee training sessions & 7 \\
Informal grapevine & 5 \\
Other - & 1 \\
CEO message & \\
\hline
\end{tabular}


sessions'. Another feature of interest was that 5 out of the 10 respondents identified the 'informal grapevine' as being an important communication type in relation to organisational change.

As indicated in Exhibit 11, there were nineteen links specifically related to employees' reaction to the uncertainty that resulted from changes to organisational strategy associated with the global financial crisis. From the links developed from the key words used in participants' responses, three major categories of reaction were identified; viz., categories based on opinion, assumption and principle which defined the level of intensity of employee reaction.

The three categories match three levels of awareness as a basis for action. At the 'consciousness' level, one is aware of the existence of uncertainty without it creating a strong emotional response; i.e., there is a balanced, if not positive approach. At the 'concern' level, one's consciousness of the situation is rather more serious and one feels more engaged emotionally. Finally, the 'reaction' level of one's emotional connection to the issue is strong and critical to the stage of creating serious stress and a negative response, even in association with others.

Similarly, participants' were asked about their own, personal reaction to the uncertainty that resulted from changes to organisational strategy associated with the global financial crisis. Again, the same

\begin{tabular}{|c|c|}
\hline \multicolumn{2}{|c|}{ Exihibit 11. Employee's Reaction to Uncertainty } \\
\hline Links & Categories \\
\hline $\begin{array}{l}\text { Not too bad for business } \\
\text { Limited uncertainty } \\
\text { Effects moderate } \\
\text { Awareness of environment/changes } \\
\text { Employees reacted well overall } \\
\text { Open \& transparent organisation }\end{array}$ & Consciousness \\
\hline $\begin{array}{l}\text { Unsettled by redundancies } \\
\text { Some concern but staff understood and accepted necessary } \\
\text { changes } \\
\text { A little stressed } \\
\text { Not happy about salaries - all staff had financial commitments }\end{array}$ & Concern \\
\hline $\begin{array}{l}\text { Staff feel threatened } \\
\text { Nothing safe } \\
\text { Uncertainty about industry as a whole } \\
\text { Uncertainty about keeping jobs } \\
\text { Worried about jobs } \\
\text { A lot of unrest } \\
\text { Threat of industrial action } \\
\text { Friction \& trouble over lost jobs } \\
\text { Some in union disrupted operations }\end{array}$ & Reaction \\
\hline
\end{tabular}

\begin{tabular}{|l|l|}
\hline \multicolumn{1}{|c|}{ Exihibit 12. Participants' Reaction to Uncertainty } \\
\hline \multicolumn{1}{|c|}{ Links } & \multicolumn{1}{|c|}{ Categories } \\
\hline $\begin{array}{l}\text { No problems } \\
\text { Heavy workload caused fatigue } \\
\text { Knew job was safe } \\
\text { Needed time to reassure staff } \\
\text { Needed time to keep staff up-to-date } \\
\text { Not really affected - some workload increase } \\
\text { Didn't feel threatened myself }\end{array}$ & \\
\hline $\begin{array}{l}\text { Limited uncertainty } \\
\text { Some concern } \\
\text { Accepted necessary changes } \\
\text { Mostly worried about having to retrench people } \\
\text { Was worried then relieved when I didn't lose my job }\end{array}$ & \\
\hline [No responses] & Concern \\
\hline
\end{tabular}




\begin{tabular}{|l|l|}
\hline \multicolumn{2}{|c|}{ Exihibit 13. Organisational Support for Employees } \\
\hline \multicolumn{1}{|c|}{ Links } & \multicolumn{1}{|c|}{ Categories } \\
\hline $\begin{array}{l}\text { Retain open dialogue } \\
\text { Honesty } \\
\text { Consultation with union reps } \\
\text { Uses an inclusive, consultative model }\end{array}$ & Plus \\
\hline $\begin{array}{l}\text { It doesn't } \\
\text { Not much concern shown really } \\
\text { Predominant culture is 'avoid' } \\
\text { Respond aggressively } \\
\text { Not well done } \\
\text { Little support offered } \\
\text { Uncertain business } \\
\text { No specific action to handle employee reactions }\end{array}$ & \\
\hline $\begin{array}{l}\text { Management surveys - feedback loops } \\
\text { Numerous 'open-space' meetings to allow wide-ranging contri- } \\
\text { butions } \\
\text { Managers mainstay for employee relations }\end{array}$ & Interesting \\
\hline
\end{tabular}

three categories were used (Table 12). In this case, no research participants indicated that they were in the 'reaction' group. Judging from the links in the other two categories, it may be argued that, as senior officers in their organisation, they were aware of the uncertainty, but not threatened directly by it.

Finally, participants were asked to describe how their organisation coped with employee responses caused by the uncertain economic climate of the crisis. Fifteen different links were identified from key words used in the responses (Exhibit 13). One means of categorising the responses was to separate them into positive (Plus), negative (Minus) and neither plus nor minus (Interesting) groups using the PMI model (De Bono 1993).

\section{DISCUSSION OF FINDINGS AND CONCLUSION}

Although, no research participants indicated that they were in the reaction to the crisis group or they were threatened by crisis and uncertainty (this can be explained by our sample characteristics, e.g. location in a wealthy state of Western Australia which was not significantly affected by the 2008 financial crisis), all of them admitted their awareness of the crisis and uncertainty. All respondents expressed an urgent need for improved communication both within and outside organisations, e.g. having meetings with key stakeholders and with other staff members in order to integrate and exchange knowledge from outside the organisation. This is aligned with previous studies (e.g. Savory, 2006) which reported that challenges of the economic environment require not so much discovery of novelty, rather, such environment requests rationalization and reconfiguring of existing knowledge. Our data demonstrates that the learning of new knowledge and rediscovery of existing knowledge is happening in collaboration with business associates and other actors of organisational nets. This finding also supports the previous literature on the role of strategic nets intentionally created by organisations and particularly intensively used in time of uncertainty as "safety nets".

This study investigated how organisations can identify new opportunities by prompt response to the challenges of the dynamically changing environment and flexible movement towards the market demand. This study is adding to the dynamic resource-based view of strategy by incorporating the assessment of the business networks of the chosen organisation and investigating how the organisation is learning from its clients and other network participants. Our finding is that in time of crisis and uncertainty organisations source the knowledge both within and outside. Our data highlights that uncertainty promote organisations' quest for ongoing learning, consultancy and collaboration with key stakeholders, closer customer and supplier involvement in product and service specification for major customers, and fostering knowledge exchange. 
The results provide insight into the organisational learning in networks and developing dynamic capabilities in response to the changes in the external environment. Because organisations learn from the environment, including through their business networks, they can foster their internal knowledge transfer and organisational learning. This flexibility and speedy response to the market enable organisations to develop new sources of a competitive advantage and sustain existing competitive advantage. Organisational learning and knowledge are key drivers of dynamic capabilities which allow organisations to respond to the challenges of the complex and dynamic environment. 


\section{REFERENCES}

Aronson, J. 1994 “A pragmatic view of thematic analysis". The Qualitative Report, 2 (1), Spring, 3 pages.

Barney JB. 1986. Strategic factor markets: expectations, luck, and business strategy. Management Science 32(10): 1231-1241

Bierly, P. and Chakrabarti, A. (1996). Generic Knowledge Strategies in the U.S. Pharmaceutical Industry. Strategic Management Journal 17 (Winter Special Issue): 123-135.

Boisot, M. and Lu, X. H. (2007). Competing and Collaborating in Networks: Is Organizing Just a Game?. Strategic Networks: Learning to Compete, Strategic Management Society Book Series. Gibbert, M., and Durand, T., (Eds), Oxford: Blackwell Publishing, 2007.

Creswell, J.W. 2003 Research design: Qualitative, quantitative and mixed methods approaches, $2^{\text {nd }}$ edn. Thousand Oaks, CA; Sage Publications.

Creswell, J.W. 1998 Qualitative inquiry and research design: Choosing among five traditions. Thousand Oaks, CA; Sage Publications.

Cunha, M. P e and Cunha, J. V. da (2006). Towards a complexity theory of strategy, Management Decision, 44 (7): 839-850.

De Bono, E. 1993 Serious Creativity. New York, NY; HarperBusiness.

Doz, Y. (2007). The Need for Strategic Agility: How to Induce Strategic Renewal and Rebuild Corporate Strategies, Copenhagen Conference on Strategic Management, 11-12 December, Copenhagen Business School.

Døving, E. and Gooderham, P. N. (2008). Dynamic Capabilities as antecedents of the scope of related diversification: the Case of Small Firm Accountancy practices Strategic Management Journal, 29: 841 -857 .

Dyer, J. H. and Wujin, C. (2000). The determinants of trust in supplier-automaker relationships in US, Japan and Korea, Journal of International Business Studies, 31 (2): p. 259-285.

Eisenhardt, Kathleen (1989), 'Building Theories from Case Study Research', Academy of Management Review, 14, 4.

Eisenhardt, K. M. and Brown, S. L. (1998). Time pacing: competing in markets that won't stand still, Harvard Business Review, 76: 59-69.

Eisenhardt, K.M. and Martin, J.A. (2000), 'Dynamic Capabilities: What Are They?', Strategic Management Journal, 21:3, 1105-1121.

Giorgi, A.P. and Giorgi, B.M. 2003 The descriptive phenomenological psychological method. In P.M. Camic, J.E. Rhodes and L.Yardley (eds), Qualitative research in psychology: Expanding perspectives in methodology and design. Washington, DC; American Psychological Association. .

Gulati, R. N., Nohria, N, and Zaheer, A. (2000). Strategic Networks. Strategic Management Journal , Special Issue 21 (3): $203-215$

Hamel, G. and Valikangas, L. (2003), 'The Quest for Resilience', Harvard Business Review September, 52-63.

Hitt, M., Keats, B., Demarie, S. (1998). Navigating in the new competitive landscape: building strategic flexibility and competitive advantage in the $21^{\text {st }}$ century, Academy of Management Executive, 12 (4): 22-43. 
Hong, J., Kianto, A. and Kyläheiko, K. (2008) Moving Cultures and the Creation of New Knowledge and Dynamic Capabilities in Emerging Markets Knowledge and Process Management , 15 (3): 196202.

Huemer, L. (2004). Activating trust: the redefinition of roles and relationships in an international construction project. International Marketing Review, 21 (2): 187- 201.

Jabri, M. 2006 "Narrative genre, social context, and the management of people: Intimations from the PRC. Asia Pacific Journal of Human Resources, 44 (3), 364-373.

Jansson, H. and Sandberg, S. (2008). Internationalization of small and medium sized enterprises in the Baltic Sea Region. Journal of International Management, 14 (1), 65-77.

Judge, B. and Blocker, M (2008) Assessing.Organizational Capacity for Change:Evolution of a Research Stream European Journal of Management, 24 (4), 15-28

Liu, T-L. (2005). Impacts on Improvement of Organisational Synthetic Value Caused by social Network Relationship, Journal of American Academy of Business, 6 (1): 102-109.

Luo, Y. (2003). Industrial dynamics and managerial networking in an emerging market: the case of China. Strategic Management Journa, 24 (13): 1315-1327

McEvily, S. K., Eisenhardt, K.M., and Prescott, J.E. (2004). The global acquisition, leverage and protection of technological competencies. Strategic Management Journal August-September Special Issue 25(8-9): 713-722.

Minzberg, H. (1994). The rise and the fall of strategic planning. New York: Free press.

Möller, K. I. and Rajala, A. (2007). Rise of strategic nets - new models of value creation. Industrial Marketing Management, 36, 895-908.

Möller and Svahn (2003) Managing Strategic Nets: A Capability Perspective Marketing Theory, 3 (2): 209-234.

Penrose, Edith T. (1959), The theory of the growth of the firm. Oxford: Basil Blackwell.

Powel, W. W. (1990). Neither market nor hierarchy: network forms of organisation, in L. L. Cumming and B. m. Staw (eds.) Research in Organisational Behaviour: 295-336. Greenwich, CT: JAI Press.

Rumelt, D.P., (1984), Towards a Strategic Theory of the Firm. Alternative theories of the firm; 2002, (2) pp. 286-300, Elgar Reference Collection. International Library of Critical Writings in Economics, vol. 154. Cheltenham, U.K. and Northampton, Mass.: Elgar; distributed by American International Distribution Corporation, Williston, Vt.,

Russell, R.C. 2006 "Expatriate managers' immersion in another culture: a phenomenological study of lived experiences". A PhD dissertation. Perth, Western Australia; Curtin University of Technology.

Savory, C., (2006). Translating knowledge to build teachnological competence. Management Decision, 44 (8): 1052-1075.

Stacy, R. E. (1996). Complexity and creativity in organisations. San Francisco, CA: Berret-Koehler.

Teece, D. J., Pisano, G., and Shuen, A. (1997). Dynamic capabilities and strategic management. Strategic Management Journal 18(7): 509-553.

Tripsas M. (1997). Unraveling the process of creative destruction: complementary assets and incumbent survival in the typesetter industry. Strategic Management Journal , Summer Special Issue 18: 119 -142 .

Tsoukas, H. (1996). The firm as a distributed knowledge system: a constructionist approach, Strategic Management Journal, 17: 11-25. 
Wernerfelt, B. (1984). A resource based view of the firm. Strategic Management Journal 5: 171-180.

Winter, Sidney G. (2000). The satisficing principle in capability learning. Strategic Management Journal, 21: 981-996.

Yin, R.K. 1984 Case Study Research: Design and Methods. Applied Social Science Research Methods Series, Volume 5. Beverley Hills, CA; Sage Publications.

Young, G., Smith, K., and Grimm, C. (1996). Strategic flexibility in information technology alliances: the influence of transaction cost economies and social exchange theory, Organisation Science, 10 (4): 439-459. 